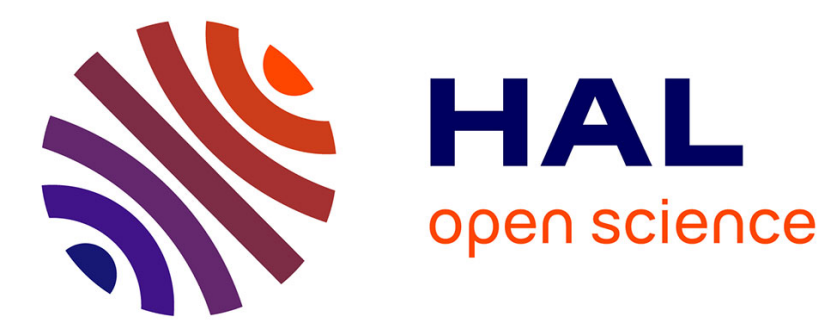

\title{
Recoverable Strains in Shape-Memory Polycrystals
}

K. Bhattacharya, R. Kohn

\section{To cite this version:}

K. Bhattacharya, R. Kohn. Recoverable Strains in Shape-Memory Polycrystals. Journal de Physique IV Proceedings, 1995, 05 (C8), pp.C8-261-C8-266. 10.1051/jp4:1995836 . jpa-00254085

\section{HAL Id: jpa-00254085 https://hal.science/jpa-00254085}

Submitted on 1 Jan 1995

HAL is a multi-disciplinary open access archive for the deposit and dissemination of scientific research documents, whether they are published or not. The documents may come from teaching and research institutions in France or abroad, or from public or private research centers.
L'archive ouverte pluridisciplinaire HAL, est destinée au dépôt et à la diffusion de documents scientifiques de niveau recherche, publiés ou non, émanant des établissements d'enseignement et de recherche français ou étrangers, des laboratoires publics ou privés. 


\title{
Recoverable Strains in Shape-Memory Polycrystals
}

\author{
K. Bhattacharya and R.V. Kohn* \\ Division of Engineering \& Applied Science, Mail Code 104-44, California Institute of Technology, \\ Pasadena, CA 91125, U.S.A. \\ * Courant Institute of Mathematical Sciences, 251 Mercer Street, New York University, New York, \\ NY 10012, U.S.A.
}

\begin{abstract}
Many alloys display the shape-memory effect in single crystal form, however the degree to which they retain this effect in polycrystalline form varies widely. We propose a theoretical explanation for this difference, showing that the recoverable strain of a polycrystal depends on the texture of the polycrystal, the transformation strain of the underlying martensitic transformation and especially critically on the change of symmetry during the underlying transformation. Roughly, we find that the greater the change in symmetry during transformation, the greater the recoverable strain. Our results agree with experimental observations, and provide guidance for the improvement of the shape-memory effect in polycrystals.
\end{abstract}

\section{INTRODUCTION}

Shape memory behavior is the ability of certain materials to recover, on heating, apparently plastic deformation sustained below a critical temperature. A large number of alloys are known to display this effect in single crystal form. However, the degree to which they retain this effect in polycrystalline form varies widely. In this paper, we provide a framework for understanding this difference in polycrystalline shape-memory behavior.

Saburi and Nenno[1] have given a qualitative but very insightful discussion about recoverable strains. Our work can be seen as an attempt to make their ideas more quantitative. The source of the shape-memory effect is a martensitic phase transformation: deformation is recoverable because it is due not to slip, but rather to rearrangement of martensite variants. Thus, the strains that can be recovered are exactly those that can be attained by the rearrangement of martensitic variants. In this paper, we estimate these recoverable strains for different shape-memory polycrystals. We find that the class of recoverable strains of a polycrystal depends not only on the texture of the polycrystal and the transformation strain of the underlying martensitic transformation, but critically on the change of symmetry during the underlying transformation. Briefly, a small change in symmetry implies little or no recoverable strain and vice versa. The main predictions are summarized in Table 2. They compare well with experimental observations as shown in Table 3.

The critical dependence on the underlying change of symmetry can be understood as follows. In an alloy undergoing cubic to tetragonal transformation, the deformations that each grain can undergo by rearrangement of martensite variants are limited to a few strain directions due to the small number of variants. Hence in the absence of special texture, any deformation of the polycrystal leads to mismatch and damage at grain boundaries and tri-junctions. In alloys undergoing cubic to monoclinic transformation on the other hand, the grains can undergo some deformation in each deviatoric strain direction by rearranging the martensite variants. Therefore the polycrystal can undergo some deformation in each deviatoric strain direction. Further, the grains have a greater freedom to deform cooperatively in this case, which may lead to greater strains being recoverable. Finally, even in textured polycrystals, small deviations in the texture are more damaging in alloys with small change of symmetry than in those with large change of symmetry. Crudely, the situation is similar to polycrystalline plasticity: for a polycrystalline material to be ductile, it is important that the crystal have sufficiently many slip systems. 
Table 1: Transformation Strains

\begin{tabular}{|c|c|c|c|}
\hline $\begin{array}{l}\text { Symmetry of } \\
\text { martensite }\end{array}$ & $k$ & $\begin{array}{l}\text { Transformation } \\
\text { Strain } e^{(1)}\end{array}$ & Examples with measured parameters \\
\hline Tetragonal & 3 & {$\left[\begin{array}{lll}\alpha & 0 & 0 \\
0 & \alpha & 0 \\
0 & 0 & \beta\end{array}\right]$} & $\begin{array}{l}\mathrm{Ni}-36.8 \mathrm{Al}(\text { at.\% })[5,6](\alpha=-0.0608, \beta=0.1302) \\
\mathrm{Fe}-30.7 \mathrm{Ni}-0.3 \mathrm{C}[7](\alpha=0.1241, \beta=-0.1941)\end{array}$ \\
\hline Trigonal & 4 & $\begin{array}{lll}\beta & \alpha & \alpha \\
\alpha & \beta & \alpha \\
\alpha & \alpha & \beta\end{array}$ & Ti-50.5Ni(at.\%)(R-phase) [8] $(\alpha=0.0047, \beta=0.0)$ \\
\hline Orthorhombic & 6 & $\begin{array}{lll}\alpha & \delta & 0 \\
\delta & \alpha & 0 \\
0 & 0 & \beta\end{array}$ & $\begin{array}{c}\gamma_{1}^{\prime} \mathrm{Cu}-14 \mathrm{Al}-4 \mathrm{Ni}[9](\alpha=0.0425, \beta=-0.0822 \\
\delta=0.0194)\end{array}$ \\
\hline Monoclinic-I & 12 & $\left.\begin{array}{lll}\alpha & \delta & \epsilon \\
\delta & \alpha & \epsilon \\
\epsilon & \epsilon & \beta\end{array}\right]$ & 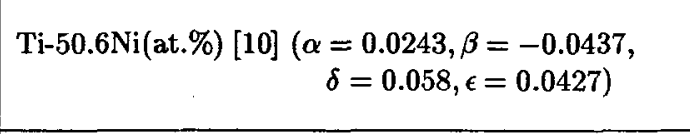 \\
\hline Monoclinic-II & 12 & $\begin{array}{ccc}\alpha+\epsilon & \delta & 0 \\
\delta & \alpha-\epsilon & 0 \\
0 & 0 & \beta\end{array}$ & $\begin{aligned} \beta_{1}^{\prime} \mathrm{Cu}-14 \mathrm{Al}-4 \mathrm{Ni}[11](\alpha=0.0442, \beta & =-0.0822 \\
\delta=0.016, \epsilon & =0.06)\end{aligned}$ \\
\hline \multicolumn{4}{|c|}{$\begin{array}{l}\text { We assume that the symmetry of the austenite is cubic. All strains are given in the cubic basis. } \\
\text { There are two kinds of cubic to monoclinic transformation. In Monoclinic-I, the axis of monoclinic symmetry } \\
\text { corresponds to }\langle 110\rangle_{\text {cubic }} \text { while in Monoclinic-II, the axis of monoclinic symmetry corresponds to }\langle 100\rangle_{\text {cubic. }} \text {. } \\
\text { Similarly, there are two kinds of cubic to orthorhombic transformation; we consider only one kind in this } \\
\text { paper since we are unaware of any example of the other. } \\
\text { We choose variant } 1 \text { so that } \delta>0 \text { and } \epsilon>0 \text {. }\end{array}$} \\
\hline
\end{tabular}

Our purpose is to understand the potential shape-memory effect inherent in the fundamental crystallography of a material. Therefore, we focus on estimating the recoverable strains. A variety of effects contribute to the actual failure of shape-memory polycrystals: brittle grain boundaries, segregation at grain boundaries and elastic anisotropy are a few examples. We do not address these issues. Neither do we attempt to obtain constitutive models for polycrystalline shape-memory based on those for single crystals.

In this short paper, we explain our ideas and report the main results. We refer to Bhattacharya and Kohn [2] for details and an extensive survey of the experimental literature. For mathematical justification of the Taylor estimate, see Bhattacharya and Kohn [3].

\section{RECOVERABLE STRAINS IN A SINGLE CRYSTAL}

Consider a single crystal of high temperature phase, austenite. We assume that the symmetry of the austenite is cubic. As the crystal is cooled, the transformation takes place, creating a mixture of the variants of the low temperature phase, martensite. The number $k$ of martensite variants is given by the change in symmetry during transformation. Let $e^{(1)} \ldots e^{(k)}$ be the stress free strains or transformation strains associated with the different variants. The strains $e^{(\mathbf{1})} \ldots e^{(k)}$ are symmetryrelated; they may be calculated from the lattice parameters of the austenite and the martensite. The transformation strains of a few important transformations are given in Table 1. All strains are given in the cubic basis. We need only specify $e^{(1)}$; then $e^{(2)} \ldots e^{(k)}$ may be obtained by means of symmetry. We emphasize that by variants we mean the "lattice correspondence variants" which are associated with changes in crystal structure, not the 24 "habit-plane variants" or "plate variants" associated with austenite twinned-martensite interfaces (see [1] or [3] for more on this distinction).

While the transformation strain of each variant is different, the macroscopic effect of the transformation is negligible due to self-accommodation between the different variants. When the specimen is deformed, the, variants rearrange themselves, so as to remain essentially stress-free by changing the microstructure. The resulting deformation appears macroscopically plastic: there is no restoring force, 
since the variants in their new configuration are not stressed. But in fact it is recoverable: heating the crystal above its transformation temperature turns each variant of martensite back to austenite and the crystal springs back to its original shape. Notice, however, that only certain strains can be recovered: those that can be achieved by the rearrangement of martensite variants. Larger strains will introduce stress, leading to lattice defects and nonrecoverability. Thus the strains recoverable in a single crystal are those which can be accommodated by rearrangement of martensite variants without the introduction of significant stresses. We shall denote by $\mathcal{S}$ this class of recoverable strains for $a$ single crystal. It consists of the average strains of coherent microstructures of essentially stress-free variants. We emphasize that only coherent microstructures are associated with recoverability.

There is a simple method for determining $\mathcal{S}$ in most cases. If each pair of variants is compatible or twin related, then every possible average of transformation strains can actually be attained by a coherent microstructure [4]. Therefore, for such materials, the class of recoverable strains of a single crystal is

$$
\mathcal{S}=\left\{e \| e=\sum_{n=1}^{k} \lambda^{(n)} e^{(n)} \text { where } \lambda^{(n)} \geq 0 \text { and } \sum_{n=1}^{k} \lambda^{(n)}=1\right\} .
$$

In transformations with tetragonal, trigonal or orthorhombic martensite each pair of variants is indeed twin related and we may use (1) to calculate this set. In both kinds of cubic to monoclinic transformation, some pairs of variants are not twin-related and in fact the formula (1) is false. However, we are still able to provide an estimate (see [2] for details).

The set $\mathcal{S}$ has the following important properties:

1. Since the variants are symmetry related, they are of equal volume. Therefore, the trace of each matrix in $\mathcal{S}$ is equal, i.e., $\mathcal{S}$ is effectively a set of deviatoric strains. Furthermore, if the austenite is cubic, $\mathcal{S}$ always contains the self-accommodating state $\mathcal{I}=\frac{1}{3} \operatorname{trace}\left(e^{(1)}\right)$ Identity Matrix.

2. In the case of tetragonal martensite, the set $\mathcal{S}$ contains only diagonal matrices. Therefore, $\mathcal{S}$ does not span the deviatoric strains; rather it lies in a lower dimensional subspace. As a result, this material is unable to recover any strain in some directions. The set $\mathcal{S}$ is also lower dimensional in the case of trigonal martensite. In contrast, the set $\mathcal{S}$ spans the deviatoric strains in the case of orthorhombic and monoclinic martensites. Therefore, in both these materials, the single crystal is able to recover at least some strain in any deviatoric direction. We will find that this difference is critical in the behavior of polycrystals.

\section{RECOVERABLE STRAINS IN A POLYCRYSTAL}

Now consider a polycrystal of austenite. We may describe the texture of the polycrystal (the orientation of the grains) by a spatially dependent rotation $R(x)$ : at any point $x$, the rotation matrix $R(x)$ tells us the orientation of the grain situated at $x$ with respect to the reference single crystal. When we cool the polycrystal, each grain transforms to a self-accommodated mixture of martensitic variants. From the arguments in the previous section, each grain has a class of recoverable strains which it can accommodate by a microstructure of martensite variants. We denote by $\mathcal{S}(x)$ the recoverable strains of the grain containing $x$. It is obtained from the set $\mathcal{S}$ defined earlier by rotating it through $R(x)$, i.e., $\mathcal{S}(x)=R(x) \mathcal{S} R^{T}(x)$.

Now deform the polycrystal. The deformation is recoverable if it can be accommodated by the rearrangement of variants in each grain. Due to the different orientations of the grains, the strain field may not be homogeneous. The macroscopic strain suffered by the polycrystal is the (spatial) average of this strain field. Therefore, we define the class of recoverable strains of a polycrystal, which we denote by $\mathcal{P}$, as the set of all macroscopic strains that can be obtained as the averages of strain fields which can be accommodated in each grain by a microstructure of martensite variants. In other words, the recoverable strains of the polycrystal are the averages of those strains fields $e(x)$ that satisfy: $e(x)$ belongs to $\mathcal{S}(x)$ at each point $x$.

Notice that we allow our grains to form fine-scale microstructure. This is an important assumption. In effect, we are assuming that the length scale of the microstructure of the variants is much smaller that the typical grain size. We believe this is a reasonable assumption in general (for example see $[12,13,14])$ though we are aware of examples where it fails. See [3] for a discussion. 
In order to calculate $\mathcal{P}$, we need to study strain fields in the polycrystal. The grains are unable to deform freely because each grain is constrained by its neighbors. Therefore, the strain fields can be quite complicated and it is quite difficult to calculate the set $\mathcal{P}$. However, there is a simple estimate analogous to the "Taylor Bound" of polycrystalline plasticity: Suppose the polycrystal is subjected to a macroscopic or average strain $e$. Also suppose that the strain $e$ is recoverable in each grain of the polycrystal, i.e., $e$ belongs to $\mathcal{S}(x)$ for each point $x$ in the polycrystal. Then, $e$ is clearly recoverable in the polycrystal, i.e., $e$ is in $\mathcal{P}$. Thus, the class of recoverable strains of a polycrystal $\mathcal{P}$ contains the class of strains

$$
\mathcal{T}=\bigcap_{x \in \Omega} \mathcal{S}(x)=\left\{e \| R^{T}(x) e R(x) \in \mathcal{S} \text { for each } x \in \Omega\right\}
$$

We call $\mathcal{T}$ the Taylor estimate. The physical meaning of the Taylor estimate is clear. It describes the strains which can be accommodated without making use of any cooperative effects between the grains. Indeed, by choosing $e(x)$ to have constant value $e$, we eliminate the need for any grain to take into account what its neighbor is doing. Rather, each grain may simply adjust its own microstructure.

We calculate the Taylor estimate for the different cases in [2]. Here we simply note a few key points:

1. The sets $\mathcal{T}$ and $\mathcal{P}$ are not empty when the austenite is cubic. Indeed, the matrix $\mathcal{I}$ belongs to $\mathcal{S}$ and $R^{T} \mathcal{I} R=\mathcal{I}$ for all rotations $R$, so $\mathcal{I}$ belongs to $\mathcal{T}$ and hence also to $\mathcal{P}$. This tells us that irrespective of the texture, there is a self-accommodating microstructure available to the polycrystal during the transformation; it can transform to this state and remain essentially stress free.

2. In the case of cubic to tetragonal or cubic to trigonal transformations, the set $\mathcal{T}$ is a single point unless the polycrystal has special texture. This is because $\mathcal{S}$ does not span the set of deviatoric strains.

3. In the case of cubic to orthorhombic or cubic to monoclinic transformation, the set $\mathcal{T}$ contains an entire ball around $\mathcal{I}$ in the space of deviatoric strains. This is because $\mathcal{S}$ does indeed span the set of deviatoric strains in these cases.

Point 2 suggests that general polycrystals of cubic to tetragonal or cubic to trigonal alloys will display no recoverable strain. We have proved in [3], using stronger methods, several results in support of this conclusion. The analysis of [3] takes into account the possibility of "cooperative effects between grains," which the Taylor estimate ignores. Point 3 assures us that in cubic to orthorhombic or cubic to monoclinic alloys, every polycrystal, irrespective of the texture, can recover at least some strain.

These statements are valid for general polycrystals. The class of recoverable strains can be significantly larger in polycrystals with special textures. We can include information about the orientation present in the polycrystal in calculating the Taylor estimate (2). We do so in [2] for uniaxial polycrystals of cubic to tetragonal and cubic to trigonal materials. For cubic to orthorhombic or cubic to monoclinic transformations, [2] concentrates on textured ribbons. Eucken and Hirsch [15] made melt-spun ribbons with the following texture: the grains are columnar with the $[001]_{\text {cubic }}$ direction of each grain perpendicular to the ribbon and either the $[100]_{\text {cubic }}$ or the $[110]_{\text {cubic }}$ direction parallel to the rolling direction. Our results for both textured and untextured polycrystals are collected in Table 2.

\section{COMPARISON WITH EXPERIMENTAL OBSERVATIONS}

Table 3 summarizes the experimental observations of recoverable strain in polycrystals made from 4 different alloys. This table also gives our predictions based on the symmetry and the transformation strain of each alloy. The agreement is quite reasonable. In particular, the main point of this paper the critical influence of the change of symmetry on the recoverable strains in a polycrystal - is very clear. The crucial role of texture is also highlighted in the experiments of Eucken and Hirsch [15]. See [2] for a more extensive literature survey and comparisons. 
Table 2: Summary of Results - Influence of Symmetry and Texture

\begin{tabular}{|c|c|c|}
\hline Martensite & General polycrystal & Textured polycrystal \\
\hline Tetragonal & No recoverable strain. & $\begin{array}{l}\text { Uniaxial polycrystal where all grains have common }\langle 100\rangle \text { direc- } \\
\text { tion: Uniaxial extension up to }\left(\max \{\alpha, \beta\}-\frac{2 \alpha+\beta}{3}\right) \text { and uniaxial } \\
\text { compression up to }\left(\min \{\alpha, \beta\}-\frac{2 \alpha+\beta}{3}\right) \text { in the }\langle 100\rangle \text { direction } \\
\text { are recoverable. }\end{array}$ \\
\hline Trigonal & $\begin{array}{l}\text { Taylor estimate suggests } \\
\text { no recoverable strain. }\end{array}$ & $\begin{array}{l}\text { Uniaxial polycrystal where all grains have common }\langle 111\rangle \text { di- } \\
\text { rection: Uniaxial extension up to } \max \left\{2 \alpha,-\frac{2 \alpha}{3}\right\} \text { and uniaxial } \\
\text { compression up to } \min \left\{2 \alpha,-\frac{2 \alpha}{3}\right\} \text { in the }\langle 111\rangle \text { direction are re- } \\
\text { coverable. }\end{array}$ \\
\hline Orthorhombic & $\begin{array}{l}\text { Every polycrystal can } \\
\text { recover at least about } \\
\frac{1}{2} \min \left\{\frac{|\alpha-\beta|}{2}, \delta\right\} \text { strain in } \\
\text { any direction. }\end{array}$ & $\begin{array}{l}\text { Ribbons with the Eucken-Hirsch texture can recover at least } \\
\left(\alpha-\frac{2 \alpha+\beta}{3}\right) \text { strain in uniaxial extension along the length of the } \\
\text { ribbon. }\end{array}$ \\
\hline Monoclinic-I & $\begin{array}{l}\text { Every polycrystal can } \\
\text { recover at least about } \\
\frac{1}{2} \min \left\{\frac{|\alpha-\beta|}{2}, \delta\right\} \text { strain in } \\
\text { any direction. }\end{array}$ & $\begin{array}{l}\text { Ribbons with the Eucken-Hirsch texture can recover at least } \\
\left(\alpha-\frac{2 \alpha+\beta}{3}\right) \text { strain in uniaxial extension along the length of the } \\
\text { ribbon. }\end{array}$ \\
\hline Monoclinic-II & $\begin{array}{l}\text { Every polycrystal can } \\
\text { recover at least about } \\
\frac{1}{2} \min \left\{\frac{|\alpha-\beta|}{2}, \delta\right\} \text { strain in } \\
\text { any direction. }\end{array}$ & $\begin{array}{l}\text { Ribbons with the Eucken-Hirsch texture can recover at least } \\
\left(\alpha+\delta-\frac{2 \alpha+\beta}{3}\right) \text { strain in uniaxial extension along the length of } \\
\text { the ribbon. }\end{array}$ \\
\hline & & \\
\hline
\end{tabular}

\section{CONCLUSION}

We have identified the recoverable strains of a shape-memory polycrystal with those which can be accommodated by the rearrangement of martensite variants. This set has been estimated for various types of polycrystals. Our main results, summarized in Table 2, correlate well with available experimental data (Table 3). Based on this insight, we recommend the following:

- For the best shape-memory effect, try to make alloys with monoclinic martensite.

- Use alloys with tetragonal or trigonal martensite only in applications where the required recovery is limited to uniaxial tension or compression. Even in such applications it is necessary to process the material, perhaps by rolling, drawing or by repeated deformation followed by annealing, to endow it with $\langle 100\rangle$ (tetragonal) or $\langle 111\rangle$ (trigonal) texture. Despite all this, it is natural to expect some unrecoverable strain.

\section{Acknowledgments}

Some of this research was conducted while KB held a post-doctoral position at the Courant Institute. This work was partially supported by grants from the AFOSR(KB), ARO (KB and RVK), NSF (KB and RVK), ONR (KB) and the Powell Foundation (KB).

\section{References}

[1] Saburi, T. and Nenno, S., "The shape memory effect and related phenomena", in Proc. Int. Conf. on Solid-Solid Phase Transformations (eds. Aaronson, H.I., Laughlin, D.E., Sekerka, R.F. and Wayman, C.M.), The Metall. Soc. AIME, New York (1981), 1455-1479.

[2] Bhattacharya, K. and Kohn, R.V., Acta Metall. Mater. in press (1995).

[3] Bhattacharya, K. and Kohn, R.V., "Elastic energy minimization and the recoverable strains of polycrystalline shape-memory materials", submitted to Arch. Rat. Mech. Anal. (1995).

[4] Bhattacharya, K. Cont. Mech. Thermodyn. 5 (1993), 205-242.

[5] Saburi, T. and Wayman, C.M., Acta. Metall. 27 (1979), 979-995. 
Table 3: Recoverable strains in a polycrystal

\begin{tabular}{|c|c|}
\hline $\begin{array}{l}\text { Alloy } \\
\text { (Martensite) } \\
\text { Key predictions }\end{array}$ & Observations in polycrystals \\
\hline $\begin{array}{l}\text { Ni-36.8\%Al(at.\%) } \\
\text { (Tetragonal) } \\
\text { No strain is fully recoverable ex- } \\
\text { cept with }\langle 100\rangle \text { texture. }\end{array}$ & $\begin{array}{l}\text { Very susceptible to intergranular fracture in tension; recovery in compression } \\
\text { limited to } 0.2 \%[16] \text {. }\end{array}$ \\
\hline $\begin{array}{l}\text { Fe-31Ni-0.4C/Fe-27Ni-0.8 } \\
\text { (Tetragonal) } \\
\text { No strain is fully recoverable ex- } \\
\text { cept with }\langle 100\rangle \text { texture. }\end{array}$ & $\begin{array}{l}75-95 \% \text { recovery of } 1-2 \% \text { bending strain and } 50 \% \text { recovery of } 5-7 \% \text { tensile strain } \\
\text { in wires. No specimen shows } 100 \% \text { recovery }[17] \text {. }\end{array}$ \\
\hline $\begin{array}{l}\text { Cu-14Al-4Ni } \\
\left(\gamma_{1}^{\prime} \text { Orthorhombic) }\right. \\
\text { Recoverable strains: At least } 1 \% \\
\text { in any polycrystal and at least } \\
4.2 \% \text { in ribbons with the Eucken- } \\
\text { Hirsch texture. } \\
\text { ( } \beta_{1}^{\prime} \text { Monoclinic-II) } \\
\text { Recoverable strains: At least } \\
1 \% \text { any polycrystal and at least } \\
5.8 \% \text { in ribbons with the Eucken- } \\
\text { Hirsch texture. }\end{array}$ & $\begin{array}{l}\text { Complete pseudoelasticity of about } 2 \% \text { tensile strain in hot-rolled plates [18]. } \\
\text { Complete recovery limited to } 2.5 \% \text { strains under compression in rods [19]. } 3.7 \% \\
\text { strain recovered from total applied } 5 \% \text { strain in fine grained polycrystals ob } \\
\text { tained by adding Boron and Zirconia [14]. Fatigue fracture occurs at strain } \\
\text { amplitude of about } 2 \% \text { in a few hundred cycles [20]. Complete recovery of } 6.5 \% \\
\text { strains in tension in meltspun ribbons with the Eucken-Hirsch texture [15]. } \\
\text { (It is not always clear whether the } \gamma_{1}^{\prime} \text { or the } \beta_{1}^{\prime} \text { martensite is involved; } \gamma_{1}^{\prime} \text { is } \\
\text { usually thermally induced while } \beta_{1}^{\prime} \text { is usually stress induced.) }\end{array}$ \\
\hline $\begin{array}{l}\text { Ti-50Ni(at.\%) } \\
\text { (R-phase Trigonal) } \\
\text { No strain is fully recoverable ex- } \\
\text { cept with (111) texture. } \\
\text { (Monoclinic-I) } \\
\text { Recoverable strains: At least } 2 \% \\
\text { in any polycrystal and at least } \\
2.4 \% \text { in ribbons with the Eucken- } \\
\text { Hirsch texture. }\end{array}$ & $\begin{array}{l}\text { R-Phase Trigonal: } 1.4 \% \text { strains recoverable in Ti-50Ni(at.\%) wire [21]. } \\
\text { Monoclinic: Wires display complete recovery of } 5.5 \% \text { strain in uniaxial exten- } \\
\text { sion [21] and } 4-8 \% \text { strain in bending [22]. Complete recovery of } 8 \% \text { tensile } \\
\text { strain in drawn wires of Ti-50.6Ni(at.\%) [23]. Complete recovery of } 6-7 \% \text { ten- } \\
\text { sile strain in hot-worked, cold-rolled and annealed strips of Ti-50.5Ni(at.\%) [12]. } \\
\text { Complete recovery of } 6 \% \text { tensile strain in hot-rolled sheets of Ti-50.4Ni (at.\%) } \\
\text { in rolling direction [24]. Complete recovery of } 6 \% \text { tensile strain in hot-rolled and } \\
\text { annealed fine grained sheets (50 } \mu \text { m grains diameter in } 0.9 \mathrm{~mm} \text { thick sheets) of } \\
\text { Ti-50.5Ni (at.\%) [25]. Complete recovery of strains } \leq 4 \% \text { in meltspun ribbons } \\
\text { with the Eucken-Hirsch texture [15]. }\end{array}$ \\
\hline
\end{tabular}

[6] Chakravorty, S., Ph.D. Thesis, Univ. Illinois, 1975.

[7] Okamoto, H., Oka, M. and Tamura, I., Trans. Jap. Inst. Metals 19 (1978), 674-684.

[8] Miyazaki, S. and Wayman, C.M., Acta Metall. 36 (1988), 181-192.

[9] Otsuka, K. and Shimizu, K., Trans. Jap. Inst. Metals 15 (1974), 103-108.

[10] Knowles, K.M. and Smith, D.A., Acta Metall. 29 (1981), 101-110.

[11] Otsuka, K., Nakamura, T. and Shimizu, K., Trans. Jap. Inst. Metals 15 (1974), 200-210.

[12] Piao, M., Otsuka, K., Miyazaki, S. and Horikawa, H., Mater. Trans. Japan Inst. Metals 34 (1993), 919-929.

[13] Miyazaki, S., Otsuka, K., Sakamoto, H. and Shimizu, K., Trans. Japan Inst. Metals 22 (1981), 244-252.

[14] Morris, M.A., Acta Metall. Mater. 40 (1992), 1573-1586.

[15] Eucken, S. and Hirsch, J., Mat. Sci. Forum 56-58 (1990), 487-492.

[16] Kim, Y.D. and Wayman, C.M., Metall. Trans. 23A (1992), 2981-2986.

[17] Kajiwara, S. and Kikuchi, T., Acta Metall. Mater. 38 (1990), 847-855.

[18] Sakamoto, H. and Shimizu, K., Trans. Japan Inst. Metals 27 (1986), 592-600.

[19] Trivero, F., Guénin, G. and Morin, M., J. de Physique III 1 (1991), Colloque C4 397-402.

[20] Sakamoto, H., Kijima, Y. and Shimizu, K., Trans. Japan Inst. Metals 23 (1982), 585-594.

[21] Ling, H.C. and Kaplow, R., Metall. Trans. 12A (1981), 2101-2111.

[22] Ling, H.C and Kaplow, R., Mat. Sci. Engng. 48 (1981), 241-247.

[23] Miyazaki, S., Otsuka, K. and Suzuki, Y., Scripta Metall. 15 (1981), 287-292.

[24] Saburi, T., Tatsumi, T. and Nenno, S., J. de Physique 43 (1982), Colloque C4, 261-266.

[25] Saburi, T., Yoshida, M. and Nenno, S., Scripta Metall. 18 (1984), 363-366. 